2016

\title{
Numeracy and Evaluating Quality in Open Access Journals
}

\author{
Carol Ann Borchert \\ University of South Florida, borchert@usf.edu \\ Jason Boczar \\ University of South Florida, jboczar@usf.edu
}

\section{Recommended Citation}

Borchert, Carol A., and Jason Boczar. "Numeracy and Evaluating Quality in Open Access Journals."

Numeracy 9, Iss. 2 (2016): Article 1. DOI: http://dx.doi.org/10.5038/1936-4660.9.2.1 


\title{
Numeracy and Evaluating Quality in Open Access Journals
}

\begin{abstract}
Evaluating quality for open access (OA) journals has long presented a challenge, complicated by the misperception that OA journals offer a lesser quality than subscription journals. OA journals, however, have a wide variety of publishing models, some of which include rigorous peer review. Numeracy has recently received the DOAJ Seal for Open Access Journals. This editorial discusses what DOAJ is and why this seal is important in the context of evaluating the quality of open access journals.
\end{abstract}

\section{Keywords}

DOAJ, OA journal evaluation, publishing models

Creative Commons License

$$
\text { (c) (i) (8) }
$$

This work is licensed under a Creative Commons Attribution-Noncommercial 4.0 License

\section{Cover Page Footnote}

Carol Ann Borchert has been the Coordinator for Serials at the University of South Florida Libraries since 2004. She has her Masters in Library Science from the University of Kentucky and has been working with open access journal publications since 2009. Her current research pertains to the various issues surrounding libraries as publishers.

Jason Boczar is the Digital Scholarship and Publishing Librarian at the University of South Florida. Jason works with the coordination of scholarly communication activities across campus. He received his Masters in Library and Information Science from the University of Kentucky in 2012. 
One of the questions editors of Numeracy have received over the years is how to evaluate the stature of this journal for promotion and tenure preparation. Numeracy has recently qualified for the DOAJ Seal of Approval for Open Access Journals, which is a wonderful honor, but what is DOAJ and what does the DOAJ Seal mean?

Quality control for open access (OA) journals is different and often more difficult than for traditional journals. Traditional journals offer easier ways to gauge quality because they are often published by well-established publishers or by well-known reputable societies. The added benefits of traditional impact factors help make assessment for traditional journals a time-tested method. OA journals face different problems. They are often created outside of the sphere of traditional publishers, forging new territory in academic publishing that lacks a solid, centralized method for evaluating journal quality.

The Directory of Open Access Journals (DOAJ) helps alleviate that lack of oversight. Their stated aim is "to increase the visibility and ease of use of open access scientific and scholarly journals, thereby promoting their increased usage and impact.” 1 More than just increasing journal visibility, DOAJ "aims to be comprehensive and cover all open access scientific and scholarly journals that use a quality control system to guarantee the content." 2

Once upon a time, anyone could submit a journal for inclusion in DOAJ by filling out a simple form that included the title, ISSN, publisher name, and URL. However, DOAJ could not ensure that the journals they listed held any particular level of quality, and many librarians and researchers even deemed some publishers to be "predatory." The print world commonly refers to this tactic as vanity publishing. A publisher might charge high article processing or author fees to make their profit, then push a submitted article through to publication quickly, with little to no peer review or copy editing. These publications mar the reputation of all OA journals, due to a misperception that all OA journals are the same.

The publishing models for OA journals vary widely and are classified as "green," "gold," "hybrid,” or "platinum.” Green OA journals allow authors to repost a version of their manuscript on an open access website or in an institutional repository such as Scholar Commons. The version permitted could be the original submitted version, the accepted version, or the final published version depending on the publisher's permissions. Gold OA journals charge fees to the authors to recover the cost of publishing, but do not charge subscription fees to readers. Springer and Elsevier represent

1 “About DOAJ,” https://doaj.org/about.

${ }^{2}$ Ibid. 
two of the primary publishers at this level, and use a stringent peer review process common for Gold OA. Hybrid OA journals are usually subscription journals that allow authors the option to pay a fee to make their particular article open access for readers. A hybrid journal might also allow open access to subscription content after an "embargo" period, meaning that, for example, a reader would need to pay a subscription fee to access the most current six months of content, but could access older content for free. Numeracy is what's called a "platinum" OA journal, where it is fully open access with no subscription costs, no embargo on the content, and no fees charged to the authors. This is made possible through free platform hosting by the University of South Florida Tampa Library, dedicated support from the National Numeracy Network, and the hard work of editors and reviewers who ensure rigorous peer review, copy editing, and layout work to provide a polished final product.

DOAJ began implementing a new application process to provide more quality control over accepted journals in 2014. ${ }^{3}$ The new application process includes up to 60 questions about the applicant's proposed journal, as well as links to the journal's policies and editorial board. At a minimum, journals must have the following characteristics:

- be scholarly in nature

- have an editorial board and associated policies listed clearly on the journal's site

- clearly explain the quality control system and type of peer review process

- provide detailed author guidelines

- clearly state if any fees are or are not charged to authors

- allow full open access to all content with no embargo period and provide a statement thereof

- have at least one ISSN number

- have its own, dedicated URL

- be actively publishing (at least 5 articles per year), with the majority being research and/or review papers $^{4}$

In order to qualify for the additional status of the DOAJ Seal of Approval for Open Access Journals, a journal must fulfill seven additional criteria:

- use DOIs as permanent identifiers

- $\quad$ provide DOAJ with article metadata

\footnotetext{
3 "What You and Your Editors Should Know about the New DOAJ Application," https://blog.digitalcommons.bepress.com/2014/11/25/what-you-and-your-editors-should-know-about-thenew-doaj-application/.

4 “Information for Publishers,” https://doaj.org/publishers.
} 
- deposit content with a long term digital preservation or archiving program

- embed machine-readable Creative Commons (CC) licensing information in articles

- allow generous reuse and mixing of content, in accordance with a CC BY, CC BY-SA or CC BYNC license

- have a deposit policy registered with a deposit policy registry

- allow the author to hold the copyright without restrictions ${ }^{5}$

Numeracy has qualified for the DOAJ Seal of Approval by meeting all of these criteria. Authors retain copyright, and Numeracy is published under a CC BY-NC license, which allows for non-commercial reuse of the content. ${ }^{6}$ All content is preserved in LOCKSS and Portico, which are both nationwide preservation systems. ${ }^{7}$ All issues and articles have digital object identifiers (DOIs), registered with CrossRef, which is a national registry facilitating the process of finding, linking, and citing content. ${ }^{8} \mathrm{~A}$ DOI provides a permanent URL for each item. For example, Numeracy moved in 2012 from its previous website at http://services.bepress.com/numeracy to its current site at http://scholarcommons.usf.edu/numeracy, and we re-registered all of the DOIs with the updated URLs. Anyone with an article's DOI could follow the content to the new URL, so the DOI link provides a permanent URL for the content.

Numeracy does not yet have an impact factor, but it does have a fairly high "success" rate of submissions. Of the 197 articles submitted to Numeracy since the journal's inception in January 2008 (and not counting the 16 articles in process right now), 137 of them have been research articles. (Other article types included editorials, book reviews, notes, and columns.) Of these research articles, $75 \%$ have been accepted, with authors encouraged to revise - often extensively — to meet the level of quality required by the journal. Only $25 \%$ have been rejected. If plagiarism is detected, authors are forbidden from future submissions to the journal. Downloads provide another measure of impact for the journal. As shown in Figure 1, usage of the journal has been increasing nicely over time, with a total of 135,850 downloads to date (May 2016) of the 161 papers posted online. Downloads have averaged about 2,900 per month over the past 12 months.

\footnotetext{
5 “Information for Publishers: What is the DOAJ Seal of Approval?”, https://doaj.org/publishers\#seal.

${ }^{6}$ See https://creativecommons.org/licenses/by-nc/4.0/legalcode for more information.

${ }^{7}$ See https://www.lockss.org/ and http://www.portico.org/digital-preservation/ for more information.

${ }^{8}$ See http://crossref.org/ for more information.
} 


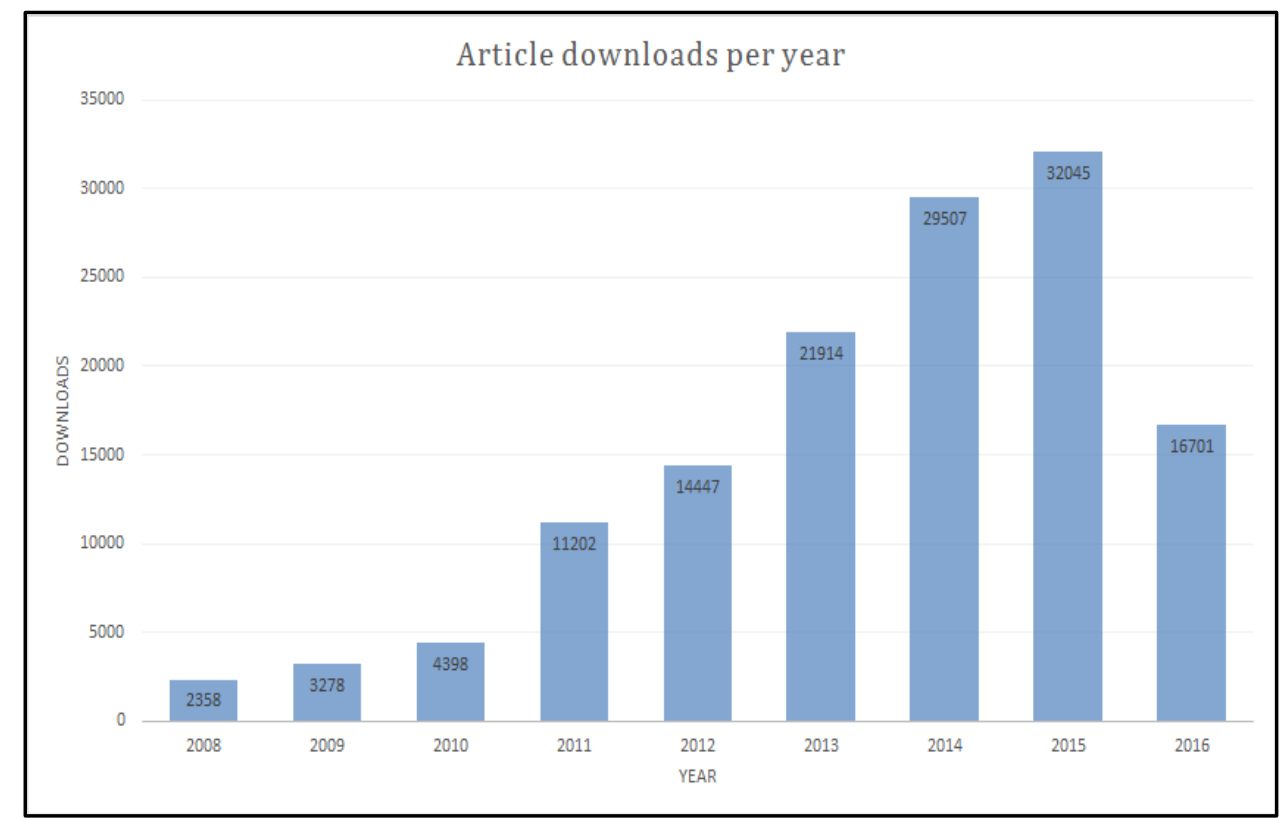

Figure 1. Numeracy article downloads per year. (Note: 2016 downloads represent a partial year, January-May 2016 downloads.)

Len Vacher stated in 2014, "People who want to think about Numeracy's statistics should know our purpose: it is to disseminate information about QL; we have standards, but our wish is that our authors meet them, rising to do so, if necessary. The role of our reviewers is not so much to screen but to help via constructive feedback."9

We look forward to many more years of quality articles from Numeracy for the QL community.

\section{References}

“About DOAJ,” Directory of Open Access Journals, accessed June 3, 2016, https://doaj.org/about.

"Information for Publishers,” Directory of Open Access Journals, accessed June 3, 2016, https://doaj.org/publishers.

"Information for Publishers: What is the DOAJ Seal of Approval for Open Access Journals (the DOAJ Seal)?”, , Directory of Open Access Journals, accessed June 3, 2016, https://doaj.org/publishers\#seal.

"What You and Your Editors Should Know about the New DOAJ Application," Digital Commons DC Telegraph, November 25, 2014, accessed June 3, 2016,

https://blog.digitalcommons.bepress.com/2014/11/25/what-you-and-your-editors-should-knowabout-the-new-doaj-application/.

\footnotetext{
${ }^{9}$ Len Vacher, email to an author, copied to Carol Ann Borchert, August 10, 2014.
} 